\title{
A negligência e a preguiça dos naturais no governo do Morgado de Mateus - aspectos discursivos e ideológicos veiculados em um ofício ascendente
}

\author{
Renata Ferreira Munhoz \\ Universidade de São Paulo (USP), São Paulo, São Paulo, Brasil \\ renatamunhoz@usp.br
}

DOI: $\underline{\text { http://dx.doi.org/10.21165/el.v45i2.813 }}$

\section{Resumo}

Este artigo analisa o discurso formulado pelo Morgado de Mateus, governador e capitão-general da capitania de São Paulo, sobre os modos de vida e costumes dos habitantes de sua área de governo. Tal discurso, contido em um ofício enviado a seus superiores em Portugal, contém marcas de cunho avaliativo, a partir das quais se vislumbram aspectos semânticos que revelam padrões ideológicos e intersubjetivos próprios do período setecentista. Com base no tratamento filológico de edição textual, realiza-se a análise discursiva a partir do viés teórico e metodológico da Teoria da Avaliatividade formulada por Martin e White (2005). Revela-se, desse modo, a esfera semântica de um texto administrativo aparentemente protocolar, mas que retrata de forma bastante expressiva a negligência e a preguiça dos habitantes da capitania de São Paulo.

Palavras-chave: Filologia; Análise do Discurso; Teoria da Avaliatividade.

The negligence and the laziness of the inhabitants of Brazil during the government of Morgado de Mateus - discursive and ideological aspects within an official letter

\begin{abstract}
This paper analyzes the discourse about the ways of life and the habits of the inhabitants of the São Paulo captaincy. The author was Morgado of Mateus, governor and captain general of that captaincy. The official letter, in which the discourse is written, was sent to his bosses in Portugal. The appraisal expressions show the semantic aspects of the discourse that reveal ideological and inter-subjective standards of the eighteenth century. Based on the philological edition of the handwritten text, the discursive analysis is supported by theoretical and methodological view of the Appraisal System Theory, a theory by Martin and White (2005). This analysis shows, therefore, the semantic level of an administrative and apparently formulaic official letter, but that expressly addresses the negligence and the laziness of the inhabitants of São Paulo captaincy.
\end{abstract}

Keywords: Philology; Discourse Analysis; Appraisal System Theory.

\section{Introdução}

Este artigo registra análises de cunho filológico e discursivo em um ofício manuscrito setecentista, produzido pelo quarto Morgado de Mateus, Dom Luís Antônio de Sousa Botelho Mourão. Como governador e capitão-general da capitania de São Paulo no período 
de 1765 a 1775, o Morgado de Mateus constantemente transmitia seus posicionamentos e opiniões sobre a área de seu governo a seus superiores em Portugal.

Por conta do destaque das marcas de valoração contidas no discurso, adotou-se o pressuposto teórico e metodológico de análise prescrito pelos australianos Martin e White (2005), a Teoria da Avaliatividade. Esse aporte permite que se observe a maneira como os autores retratam seu posicionamento pessoal, como constroem sua identidade e de que forma expressam tal ethos diante dos interlocutores, conforme orientam Martin e White (2005, p. 40).

Além da metodologia de análise empregada, trabalha-se o aspecto da intertextualidade. Isso porque o discurso do Morgado de Mateus retoma, por vezes de maneira literal, os dizeres da política pombalina contidos em outros documentos oficiais do período histórico.

Pretende-se, pois, exemplificar a maneira como os governantes ultramarinos produziam seus discursos oficiais. Ao apoiarem-se em diretrizes políticas já legitimadas socialmente pelo governo central, os governantes trabalhavam aspectos relevantes da ideologia coeva e, ao mesmo tempo, gerenciavam suas relações com os interlocutores.

A fim de retratarem-se essas questões contidas no discurso do Morgado de Mateus, o artigo organiza-se da seguinte forma: após esta breve introdução, apresenta-se a transcrição semidiplomática do documento a ser analisado, a fim de situar melhor as observações posteriores. A seguir, introduz-se uma breve abordagem de cunho filológico. Finalmente, antecedendo as considerações finais, apresentam-se as análises acerca do discurso veiculado no documento oficial setecentista.

\section{O documento em análise}

O manuscrito enviado pelo governador e capitão-general da capitania de São Paulo ao Secretário do Reino, Conde de Oeiras (Sebastião José de Carvalho e Melo, posteriormente, o Marquês de Pombal), foi formatado pela espécie documental "ofício". Por se tratar de um documento não-diplomático, que não contém suas partes completamente orientadas por fórmulas, o ofício oferece ao autor maior liberdade redacional. A escolha por este testemunho deve-se a essa maior abertura na redação, que ultrapassa a padronização e fixidez das fórmulas diplomáticas.

O conteúdo da informação é o fato de o Morgado de Mateus ter tomado a resolução de implantar a agricultura na capitania. Em virtude da extrema pobreza do local, exemplificada pela Vila de Santos, onde o governador ficara desde sua chegada de Portugal, o autor informa sobre os planos de lá instalar fábricas de algodão e de louça. Para tanto, afirma ter se adiantado em mandar virem tecelões do Rio de Janeiro para implementar a atividade industrial na região. Como argumento a seus projetos, demonstra a importância de realizar-se uma atividade econômica no local. Infere, nesse propósito, ser o desvio da rota do ouro, que já não passava pela capitania de São Paulo, a causa de tamanha pobreza.

Embora a versão fac-similar do documento esteja disponível em meio digital a partir da microfilmagem realizada no âmbito do Projeto Resgate Barão do Rio Branco, optou-se por trabalhar com a edição semidiplomática do documento. Tal edição visa a facilitar a leitura dos 
pesquisadores contemporâneos pela codificação tipográfica de grafias manuscritas, nem sempre de fácil compreensão.

A edição semidiplomática surgiu da necessidade de fixação de um modelo de reprodução textual capaz de auxiliar tanto pesquisas históricas quanto linguísticas. Nessa perspectiva, a transcrição apoia-se nas "Normas para Transcrição de Documentos Manuscritos" estabelecidas por um conjunto de pesquisadores durante o $2^{\circ}$. Seminário "Para a História do Português do Brasil" em 1998, conforme Cambraia et al. (2001, p. 13).

De modo sucinto, as normas adotadas visam ao estabelecimento fidedigno da lição original do texto. Para tanto, mantém-se a grafia e pontuação originais, sem atualização para as normas ortográficas em vigor atualmente. As fronteiras de palavras também são reproduzidas conforme a versão manuscrita, mantendo-se a união de palavras cuja escrita continha elemento de ligação. A transcrição é justalinear, de modo a manter a mesma posição dos parágrafos. Desenvolvem-se as abreviaturas, grafando em itálico as partes inexistentes no texto manuscrito.

Apresenta-se, a seguir, a referida transcrição do ofício manuscrito dentro de uma caixa de texto para melhor distinguirem-se seus limites:

\section{Número cinco}

Illustrissimo e Excellentissimo Senhor

He muito notavel asummapobreza aque

5 se achaõ reduzidos amayorparte dos habitantes destaVilla;

constandome que aestaproporcaõ sucede omesmo nas outras terras destaCapitania: elles se achaõ faltos de todo onecessario para as comodidades daVida, athe doproprio sustento, porque quazi todo the vemde fora, nascendo esta mizeria, danegligenciacom

10 que estaõ vendo econservando aopedas suas Cazas, Largas Campinas todas cobertas de arvoredo eespessamata sem utilidadealgu

a. Senaõ fosse opequeno cabedal que aqui dispendemos Solda-

dos destapoucatropa pagaque seconserva; e anecessidade que obrigaaos habitadores deSerra assima adecerem aestePorto para se

15 proverem de alguns alqueires de Sal que de mezes amezes trã portaõ alguns pequenos Navios; ja detodo estariadespovoada.

Os seus Edificios ainda mostraõ empartes ariqueza quetiveraõ os seus antepassados no tempo em que o Ouro das mi nas corriapor esteCanal; porem aodipoes que o dito ouro passou

20 pelo Rio de Ianeiro, adondehe mais convenienteporque seevita o riscode Mar, que naõ he taõ pequenoque corredeste, aquelle Porto; Sendo ariqueza do Ouro que aqui ficou hua felicidade tran zitoria 
paraaquelles em cujas maos estava; pois naõ podiapermanecer

naõ havendo emque seempregase desorte queo rendimento

25 fizese circullo, ouretrocesso outraves paraseupropiodono; pouco

apoucosefoi diminuhindo com os quotidianos gastos davida,

athe que detodo seveyo aextinguir; de maneiraquejahojese

naõ acha aqui dinheiro se naõ namaõ de huns tantos Comer

ciantes que aindahoje conservaõ humpequeno negocio.

30 Dezejando eu de alguasortedar remedio atantos

damnos, passei huaOrdem atodas as Cameras paraque obriga-

sem afazer plantaçoẽs dealgodaõ. Tratei com os principaes

Mercadores daterra paraque sejuntassem paracomprar por

precos certos todo o que viesse. Tenhomandado vir doRio de Ia

35 neiro Mestres de fabricar odito algodaõ com os seus teares, paraes -

tablecer fabrica nestaterra. Tenho falado ahum homem eote

nhodisposto para haverdeerigila egovernala. Tenhoesperancas bẽ

fundadas deque haverá quem queiraconcorrercomdinheiros para

os primeiros fundamentos.

40 O mesmo tenhopraticado para ver seposso

establecer alguas fabricas delouça pelo excelentebarro quehadeque

sefazem couzas uteis, ecuriozas.

Todas estas ideas estaõ muito nos seus principios,

Deos queira ajudarme para as aperfeicoar, e Vernoestado que

45 lhes dezejo.

Deos Guarde aVossa Excellencia Villa de Santos em

19 de Agosto de $\underline{1765}$

Illustrissimo e Excellentissimo SenhorConde

deOeyras.

50

DomLuis AntoniodeSouza.

Esse ofício, produzido em 19 de agosto de 1765 na Vila de Santos e enviado a Portugal ao Conde de Oeiras, foi catalogado por Arruda (2002, p. 352).

\section{Aspectos filológicos}

O ofício anteriormente transcrito foi grafado de próprio punho pelo Morgado de Mateus. A prática de um governante redigir textos oficiais de sua Secretaria de Governo de maneira autônoma, sem contar com a mão de secretários ou escribas, é um fato pouco recorrente no período. Em geral, os governantes ditavam os conteúdos a seus funcionários e apenas assinavam de próprio punho. Dessa prática resultam poucos registros de algumas figuras históricas, o que dificulta o reconhecimento de sua caligrafia. No entanto, essa 
dificuldade não se verifica nos estudos que envolvem o Morgado de Mateus, uma vez que grafava de próprio punho grande parte da produção documental de seu governo.

Por sua prática constante de exercitar a "arte de debuxar", como ele próprio referia-se à escrita, foi chamado pelo grande historiador Taunay (1945, p. 91) de "o homem que não tinha preguiça de escrever". Em contrapartida, pelo mesmo motivo, foi criticado pelo Conde de Oeiras. O primeiro ministro do Rei Dom José I manifestou sua aversão a trabalhos manuais em um ofício enviado ao governador de São Paulo, em que o orientava a dedicar-se a afazeres de mais relevância ao Real Serviço. Nesse sentido, a escrita era rebaixada para a esfera dos afazeres mecânicos e manuais, de menor status social.

A versão original desse ofício encontra-se arquivada no Arquivo Histórico Ultramarino em Portugal. A divulgação do conteúdo informacional foi viabilizada pela versão digital disponibilizada pelo Projeto Resgate Barão do Rio Branco a partir do processo de microfilmagem. Entretanto, a análise codicológica, que demanda o contato direto com o suporte, teve de ser realizada no próprio Arquivo português.

O original autógrafo encontra-se descrito pelo Catálogo de documentos manuscritos avulsos referentes à capitania de São Paulo do Arquivo Histórico Ultramarino, sob a cota descritiva AHU_CU_023-01, Cx. 23, D. 2241.

O suporte material é cartáceo, um papel amarelado e resistente, feito à base de tecidos, como grande parte dos papéis da segunda metade do século XVIII. A filigrana encontrada, um brasão com arabescos florais e uma árvore no cimo, demonstra que o papel era da marca holandesa "D \& C Blauw". O suporte não tem pautas. Conta com um carimbo preto circular de $25 \mathrm{~mm}$ de diâmetro, da Biblioteca Nacional - Secção Ultramarina antecedendo a mancha. Há ainda o carimbo oval do Arquivo Histórico Ultramarino, de $10 \mathrm{~mm}$ de diâmetro, ao final da mancha.

Além desses detalhes observados graças à consulta ao original, há ainda as marcas de dobradura. Esse tipo de marca permite que se compreenda a maneira como a correspondência fora enviada ao Reino. O ofício em análise, por exemplo, contém um vinco indicativo de dobra ao meio, certamente realizada para que o papel coubesse no envelope (sobrescrito). Observam-se, ainda, três marcas decalcadas em relevo redondo encostadas à marca do vinco, indicando a colocação de três selos quando a correspondência já estava contida no sobrescrito. Interessante ressaltar que nem sempre os papéis a serem despachados eram acondicionados em um envelope (sobrescrito). Comumente, as dobraduras permitiam que o verso do próprio papel se tornasse o sobrescrito.

A tinta empregada era a ferrogálica, cujo excesso de ferro pode ser visualizado pelo brilho contido nas letras do manuscrito. $\mathrm{O}$ excedente da substância causa também marcas de corrosão facilmente observáveis no suporte.

Sucintamente descritos alguns aspectos filológicos do documento, parte-se para a análise de ordem discursiva do original autógrafo anteriormente reproduzido. 


\section{Análise do discurso}

Uma vez que o discurso empregado no oficio apresenta marcas do posicionamento do autor, selecionou-se a proposta australiana "The appraisal system" (MARTIN; WHITE, 2005), traduzida para o Português como "Teoria da Avaliatividade", para embasar as análises. Isso porque o exemplar da documentação oficial administrativa setecentista estudado apresenta elementos subjetivos que indicam a perspectiva do autor no texto. Essa perspectiva é apresentada por meio de marcas linguísticas destacadas ao longo da abordagem a seguir. Ressalta-se, no entanto, que os elementos de ordem subjetiva empregados pelo autor apoiam-se sempre nas ideologias e convenções em voga naquele período. Tal correspondência é comprovada por meio da exemplificação da intertextualidade apoiada em documento oficial da época.

Sendo assim, as marcas linguísticas indicativas de valoração são estudadas devidamente por meio do sistema da Avaliatividade, que possibilita estudar o "conjunto preciso dos sistemas gramaticais que realiza estas categorias semânticas [que revelam o posicionamento do autor, com elementos (inter)subjetivos como gostos, emoções e avaliações normativas], descrevendo-os de forma teoricamente motivada, e não os deixando ao arbítrio da intuição" (AZUAGA, 2003, p. 50). Assim, a teoria da Avaliatividade ambiciona compreender como os autores constroem seu ethos; como se posicionam diante dos potenciais destinatários; e como organizam o discurso para atingirem o que intencionam com seus textos.

Esse aporte teórico e metodológico apoia-se na estrutura de três subsistemas: atitude, engajamento e gradação. Por meio da atitude, observa-se como o autor posiciona-se, de modo a retratar explícita ou implicitamente três instâncias: os seus sentimentos (afeto), pareceres sobre outras pessoas (julgamento) e visões sobre coisas (apreciação). A gradação tem a função de intensificar ou mitigar significações. Divide-se em força, que gradua as avaliações, para intensificar ou mitigar os significados; e foco, que gradua contextos não possíveis de gradação. O engajamento, por sua vez, trata de vozes diversas da autoral no discurso. Por meio da expansão dialógica, o autor demonstra adesão a posicionamentos de outrem, enquanto repele outros pontos de vista pela contração dialógica.

Em acréscimo a essa proposta teórico e metodológica apontada, emprega-se o Diretório dos índios ${ }^{1}$ como base para a comprovação de que o discurso do texto esteja filiado à tradição ideológica coeva. Trata-se de um documento pombalino de 95 artigos, publicado em 1757, dois anos após sua elaboração por Francisco Xavier de Mendonça Furtado, na então administração do Grão-Pará e Maranhão. A proposta central do texto é a de incluir os índios entre os colonizadores brancos. Para tanto, um dos tópicos é a necessidade de se adotar a língua portuguesa como idioma único, em detrimento da então falada língua-geral. Outro item trabalhado é o distanciamento dos indígenas nativos do Brasil como superiores aos africanos, a quem deveria ser reservada a tratativa de "negro".

Assim sucintamente apresentado o embasamento, segue-se com a análise do manuscrito oficial em questão.

\footnotetext{
${ }^{1}$ Diretório que se deve observar nas Povoações dos Índios do Pará, e Maranhão, enquanto Sua Majestade não mandar o contrário. Disponível em: <http://www.nacaomestica.org/diretorio_dos_indios.htm>.
} 
Em primeiro lugar, cabe destacar que a temática central do oficio é a de transmitir a Portugal, de maneira pejorativa, a forma como viviam os moradores da Vila de Santos. Para tanto, logo após a fórmula da saudação de abertura, o autor inicia: "He muito notavel asummapobreza aque | se achaõ reduzidos amayorparte dos habitantes destaVilla;" (linha 4). No fragmento, a gradação de força do epíteto "suma" intensifica o conceito de "pobreza", indicando o seu nível máximo. O atributo "reduzidos" implica a valoração de polaridade negativa, em que o julgamento denota a estima social do autor de modo a retratar sua ideologia. A carga semântica comprova que o autor considera positiva a vida com posse de mais recursos. Essa visão é a do autor, como estrangeiro que retrata a situação local com base em suas vivências pessoais, o que é chamado por Van Dijk (2012, p. 36) de "modelo mental". Dessa forma, não é possível assegurar que essa visão negativa sobre seu modo de vida pudesse existir entre os próprios moradores da Vila de Santos.

Diante dessas possíveis vozes opostas a suas considerações, introduz-se o tópico com a contração dialógica, restringindo posicionamentos contrários pela afirmação em duas ocorrências, "He muito notavel" (linha 4) e "constandome que" (linha 6). O uso desse recurso pressupõe a existência de visões diversas dessa asserção, provavelmente a dos próprios habitantes acerca de si mesmos. Cônscio dessa polêmica, o Morgado de Mateus resguarda seu ethos enquanto aquele que pronuncia conceitos comprovadamente verdadeiros. Serve-se do detalhamento da descrição com que prossegue o texto ao longo de todo o primeiro parágrafo. Emprega, para tanto, repetidos usos da gradação de força de grau alto: "suma pobreza", "a maior parte", "faltos de todo o necessário", "quase tudo the vem de fora". Esse detalhamento hiperbólico reforça o estado de decadência de recursos em que se encontravam os moradores. Na linha 9, o termo anafórico "miséria" retoma a descrição depreciativa anterior e introduz um novo viés.

Ainda nas primeiras linhas, serve-se também da Reação contida no termo "notável" para introduzir sua atitude de julgamento de estima social de polaridade negativa, com que julga a situação a partir de seus conceitos ideológicos acerca da prosperidade. Essa caracterização pejorativa das condições de vida na vila estende-se, segundo ele, a outras localidades da capitania de São Paulo, onde os moradores "se achaõ faltos de todo onecessario para | as comodidades daVida, athe doproprio sustento," (linha 7). A gradação de força escalona o fato de não terem o "necessário para as comodidades" e, em última instância por meio do advérbio "até", não terem condições para o "próprio sustento". Aparentemente refere-se aos habitantes, alvos reais da crítica, como vítimas de um processo. Usa para isso a voz passiva, com que omite o tom de acusação e suscita um teor mais paternal em relação a seus governados.

$\mathrm{Na}$ mesma vertente, vale-se da estratégia intersubjetiva de caracterizar mais explicitamente as circunstâncias do que as pessoas, sobre quem de fato faz as críticas. Decorre daí a predominância da apreciação em detrimento de julgamento em grande parte dos documentos do corpus. Ao apreciar negativamente os aspectos censurados, o autor intelectual do ofício demonstra poupar os responsáveis pela situação a fim de comprovar sua visão benevolente.

Tal postura ganha um novo contorno quando se insere o termo "negligência" na linha 9, para rotularem-se de forma mais direta os próprios moradores da Vila de Santos. Mesmo 
assim, retrata-se apenas a falta de cultivo ao redor de suas casas, ainda sem julgamentos. Pode parecer que uma apreciação tenha polaridade neutra, como quando se diz que há "largas campinas" (linha 11) e "espessa mata" (linha 12) ao pé das casas. Entretanto, levandose em consideração a polaridade semântica da sentença completa, considera-se negativa a avaliação do autor ao retratar como negligente a falta de trabalho dos moradores, que não transformavam essas campinas em espaços de cultivo da lavoura.

Desse modo, o primeiro parágrafo concentra-se nos limitados meios de sobrevivência do povo, sem os quais "ja detodo estariadespovoada" (linha 16): os rendimentos dos soldados e o comércio do sal. Os dois exemplos citados não são aleatórios. Ao empregar por duas vezes a gradação de força de grau baixo, o autor mitiga o tamanho das tropas existentes, de modo a exaltar sua importância: "Senaõ fosse opequeno cabedal que aqui dispendemos Solda- $\mid$ dos destapoucatropa pagaque seconserva" (linha 12). Embora "pequeno", é esse cabedal dispendido pelos soldados empregados na "pouca" tropa que garante a sobrevivência da população no local. A esse capital somam-se os lucros "de alguns alqueires de Sal" (linha 15) comercializados no Porto de Santos aos moradores "deSerra assima" (linha 14). Reforça-se com o grau médio da gradação "alguns" a importância do comércio. Os dois exemplos contam com gradação de sentido reverso, em que aparentemente a significação é mitigada, com a finalidade de se exaltarem as medidas centrais do governo do Morgado de Mateus: a militarização e o desenvolvimento do comércio à prosperidade local.

O segundo parágrafo discorre sobre o antigo estado de abastança, o que fundamenta a abordagem desenvolvida pelo autor no primeiro parágrafo do oficio. A maior parte dos habitantes acha-se reduzida ao estado de "suma pobreza" descrito no parágrafo anterior por uma razão externa, "o Ouro das mi | nas corriapor esteCanal; porem aodipoes que o dito ouro passou | pelo Rio de Ianeiro" (linha 18). O engajamento de contração dialógica exprime a refutação pela contraexpectativa na conjunção "porem", contrapondo explicitamente o passado de riqueza ao presente de miséria. De maneira implícita, "felicidade transitória" (linha 22) transmite a polaridade negativa de um julgamento de estima social, enfatizando a tenacidade, ao indicar o modo como os cidadãos se comportam com o dinheiro: gastam-no de forma inconsequente.

A contração dialógica de refutação pela negação demonstra a existência de vozes contrárias à mudança do caminho do ouro. Certamente essa voz provém dos próprios habitantes retratados pelo ofício, prejudicados pela alteração do fluxo do ouro. Para anular o escopo do argumento contrário às ordens do Reino, acerca do pouco risco do mar, empregase o engajamento "que naõ he taõ pequeno" (linha 21) sobrecarregado de termos avaliativos. Usa-se a valoração social negativa de "pequeno", antecedido do intensificador "taõ", a fim de retomar uma voz externa a que se nega. Mostra-se, um com isso, total concordância com as ordenações da Coroa independente dos prejuízos que tragam a sua área de governança. Esse ethos daquele que acata todas as medidas incondicionalmente, construído no início do governo, vai aos poucos sendo desconstruído apesar de seu constante esforço empreendido no nível discursivo, como se deu ao longo da própria governança do Morgado de Mateus.

A construção dos dois primeiros parágrafos baseia-se no jogo paradoxal entre os termos "miséria" (linha 10) e "riqueza" (linha 18), que contêm em si carga avaliativa implícita. 
Ambos reforçam o julgamento de estima social daqueles que superam o estado de miséria e alcançam a riqueza, seja pela capacidade ou pela tenacidade. Em seus extremos máximos da polaridade, negativa no caso de "miséria" e positiva no caso de "riqueza", esses conceitos resumem o tempo presente da produção discursiva em contraposição aos tempos pretéritos, sobre os quais os edificios dos antepassados paulistas "ainda mostram" (linha 18) a antiga riqueza. Corrobora-se, desse modo, a fama atribuída aos bandeirantes, bem como se aponta a importância das minas de ouro para a economia. A caracterização da riqueza do passado dá-se apenas "em partes" (linha 18) e esses sinais já são o bastante para o empenho do governador em reestabelecer a prosperidade, traçando metas conforme espera o Conde de Oeiras, que os povos sejam "opulentos".

Os "quotidianos gastos da vida" reduziram os lucros do ouro até que se viesse "a extinguir", mantendo-se apenas a "uns tantos comerciantes que ainda hoje conservam um pequeno negócio" (linha 28). A intensificação pela gradação de força conferida por "tantos" é em seguida mitigada pela gradação do mesmo tipo, embora de polaridade invertida, "pequeno". Com isso, a quantidade de comerciantes que ainda detêm o dinheiro oriundo da mineração de ouro não possui tamanho considerável. Essa ideia retoma o eixo central de crítica aos habitantes locais.

Em contrapartida, a atitude de julgamento de estima social negativa que atribui à população da Vila de Santos é proporcional ao mesmo tipo de julgamento, de polaridade positiva, atribuído a suas próprias atitudes: "Dezejando eu de alguasortedar remedio atantos | damnos" (linha 30). Enquanto o povo não apresenta vigor na esfera da tenacidade, ele demonstra possuir essa virtude. Confere ao terceiro parágrafo a atitude de afeto expressa pela inclinação positiva do processo mental "desejar", demonstrando o seu comprometimento em agir contra "tantos danos" descritos nos parágrafos anteriores. A quantificação dos danos realça a importância e proporção de suas ações contra eles. Ratificando tal ideia, o autor enumera suas medidas: "passei huaOrdem atodas as Cameras paraque obriga- | sem afazer plantaçoẽs dealgodaõ.". A ordem passada a "todas" as câmaras demonstra a abrangência da ação e o verbo "obrigar" demonstra a consciência de sua posição de autoridade. O fato de as Câmaras terem de obrigar esses habitantes demonstra a falta de iniciativa e a possível resistência deles. Esse comando não se demonstra tão autoritário por o mesmo verbo já ter sido empregado antes: "anecessidade que obri- | gaaos habitadores deSerra assima adecerem aestePorto" (linha 17). A forma impositiva é atenuada pelo fato de os habitantes serem de qualquer forma "obrigados" a uma atitude contrária à falta de atitude. Parece melhor que seja pela autoridade das Câmaras, que trará beneficios, do que pela imposição da "necessidade".

Sua providência de ordenar que se "obrigassem a fazer plantações de algodão", tornase válida diante da visão de que a miséria poderia ser amenizada com a produção agrícola. Em acréscimo, menciona o plano de implantar fábricas: "O mesmo tenhopraticado para ver seposso | establecer alguas fabricas delouça pelo excelentebarro quehadeque | sefazem couzas uteis, ecuriozas." (linha 42).

Após explicitar, de maneira detalhada, a implementação agrícola, brevemente menciona o projeto de estabelecer "algumas fábricas de louça", em que a gradação de força parece mitigar a quantidade desses empreendimentos. Seriam apenas "algumas" e não algo a ser estabelecido em "todas as câmaras", como as plantações. Reconhece o esforço que teria de 
empreender para levar adiante seu propósito industrial em um local do qual seus superiores desejavam apenas a produção agrícola. Assim, por meio da seleção lexical da gradação, indicando a quantidade em seu grau máximo em relação à agricultura e em seu grau médio em relação às fábricas, tenta receber a aprovação do estabelecimento das fábricas por passar despercebido em meio à implementação agrícola. A própria organização do texto reflete sua proposta. Reconhecendo que a produção rural era mais bem vista por seus superiores do que a criação de fábricas na colônia, emprega a técnica de colocar esse projeto em segundo plano e de forma bem mais sucinta. Desenvolve o terceiro parágrafo de maneira detalhada acerca das plantações de algodão e brevemente, em apenas três linhas introduz sua proposta das fábricas de louça, sobre o que justifica poderem fazer "coisas úteis e curiosas" (linha 42). A justificativa em que se emprega a apreciação de valor social positivo soma-se à modalidade "ver se posso estabelecer" (linha 40), que indica possibilidade remota. Esses dois índices retratam a previsão de possíveis ordenações contrárias de seus superiores.

Tanto a proposta relativa à implementação agrícola do algodão quanto o estabelecimento das fábricas de louça são apresentadas como derivadas da vontade de romper com os padrões de negligência vigentes, mas necessitam do aval da Coroa portuguesa. Esse pedido de autorização não é feito explicitamente, senão pelos dizeres: "Todas estas ideas estaõ muito nos seus principios, | Deos queira ajudarme para as aperfeicoar, e Vernoestado que | thes dezejo." (linha 45). Nota-se que a atitude de afeto, ao se relatar o "desejo" pessoal de ver o fruto desse trabalho parece evitar um impedimento a esses projetos. Acima disso, ao afirmar que suas ideias ainda estão no início, o autor apresenta uma postura de modéstia que se contrapõe às medidas sérias e abrangentes mencionadas nos parágrafos anteriores. Essa estratégia de rebaixamento valoriza seu ethos ao demonstrar postura de humildade. Na contramão disso, essa postura aparente esconde a sua capacidade de elencar muitas outras ideias semelhantes. Ocorre, portanto, o engrandecimento de seu ethos.

Atribui-se, no mesmo sentido, às esferas divinas a solicitação do apoio necessário para o aperfeiçoamento de suas ideias. Emprega-se, para tanto, a religiosidade no princípio da humildade católica da submissão ao indispensável auxílio de Deus. Dessa maneira, o ofício é encerrado por meio da asserção de que essas "estão muito nos seus princípios" (linha 43), de modo a valorizar as medidas já tomadas como o início de realizações maiores, embora tal posição permaneça atenuada pelo preceito religioso inserido no mesmo período.

A crítica social é reforçada pelo fato de tais moradores serem julgados, pela estima social positiva do subsistema julgamento, como detentores da capacidade de viverem com "riqueza", conforme prova, "em partes", a arquitetura remanescente desse passado. Em oposição às propostas de desenvolvimento social do Morgado de Mateus, a circulação do ouro é retratada pelo governador como "uma felicidade transitória" por ausência de meios que possibilitassem sua fixação ao local.

Diante da impossibilidade de julgar pelo parâmetro do julgamento de sanção social, os comportamentos e práticas reprováveis, o capitão general atribui à esfera da estima social a crítica ao modo de vida desses moradores. Por não poder atribuir punições que alterassem a situação de maneira imediata, propõe medidas paliativas ao quadro. 
O julgamento de estima social de polaridade negativa pressupõe a importância da agricultura à economia colonial, criticando o fato de se comprarem tantos produtos estrangeiros ao invés de os produzirem na região. Como exemplo à argumentação, são apontadas as "largas campinas, todas cobertas de arvoredo e espessa mata sem utilidade alguma" que se localizam, pela figura de linguagem "ao pé de suas casas". O reforço desse exemplo é dado pela gradação de força, com os adjetivos "largas" e "espessa" e pela de foco com o pronome indefinido "todas" e pela imagem da figura a apontar a facilidade que teriam em cultivar tais terrenos, tão próximos de suas residências.

Como consequência desse cenário apresentado, a responsabilidade do estado de "miséria" é atribuída à "negligência" dos próprios moradores. Esse posicionamento segue os preceitos da política pombalina. Prova disso é a evidente intertextualidade que o ofício apresenta em relação ao Diretório dos Índios. Como exemplo, reproduz-se um fragmento do parágrafo 17 em que os Diretores responsáveis pelo aldeamento dos silvícolas brasileiros deveriam ter a consciência em relação aos moradores de "que a sua negligência, e o seu descuido, tem sido a causa do abatimento, e pobreza, a que se acham reduzidos; não omitindo finalmente diligência alguma de introduzir neles aquela honesta, e louvável ambição, que desterrando das Repúblicas o pernicioso vício da ociosidade, as constitui populosas, respeitadas e opulentas.". Nota-se que até mesmo a terminologia da "negligência" e da "ociosidade" é reproduzida de maneira literal.

Outro aspecto trabalhado pela política pombalina é o conceito de rebaixamento dos povos a que tinham de colonizar. Nesse sentido, a ideia de "estarem reduzidos" aos estados de pobreza e ignorância é apresentada no parágrafo 3 do Diretório dos Índios: "E sendo evidente, que as paternais providências de Nosso Augusto Soberano, se dirigem unicamente a cristianizar, e civilizar estes até agora infelizes, e miseráveis Povos, para que saindo da ignorância, e rusticidade, a que se acham reduzidos, possam ser úteis a si, aos moradores, e ao Estado". O conceito tem sempre como base de comparação o que é tido como ideal ao colonizador, a realidade da Europa, portanto.

No parágrafo 19 do mesmo Diretório, há ainda a noção de fertilidade do Brasil: "E achando que os Índios não possuem terras suficientes para a plantação dos preciosos frutos, que produz este fertilíssimo País".

O emprego da mesma ideologia de seus superiores legitima a atuação do governador ultramarino, de modo a garantir que suas intervenções seriam sempre filiadas às propostas centrais da coroa portuguesa. Ao mesmo tempo, a comprovada manutenção da politica preponderante trabalha o ethos do Morgado de Mateus como cumpridor de seus deveres e digno do cargo de confiança a ele atribuído.

Ao delegar aos próprios habitantes a melhoria da situação, os governantes isentavam sua responsabilidade imediata e permitia que projetassem medidas de intervenção social mais ostensivas. Isso porque os atenuantes da miséria seriam o aspecto militar, decorrente do "pequeno cabedal" dos soldados, e o comercial, resultante da produção de sal e transportada pelo porto de Santos, ambos conceitos basilares do governo do capitão-general que grafara o oficio de próprio punho. 


\section{Considerações finais}

Intencionou-se, portanto, por meio da análise aqui apresentada no oficio enquanto um recorte da vasta documentação manuscrita setecentista produzida por governantes portugueses na colônia do Brasil, retratar o uso da linguagem na instância do discurso dessa documentação administrativa oficial, com a característica de apoiar-se na intertextualidade de documentos consagrados pela política da época.

Ao parafrasear termos e reproduzir conceitos estipulados por seus superiores como modelares, o Morgado de Mateus legitima de maneira oficial sua governança por meio do discurso.

Assim, a ideologia de colonização estipulada pela política pombalina é mantida no Brasil colonial. As marcas de valoração presentes no discurso oficial reiteram essa ideia e, ao mesmo tempo, afastam o princípio de que os textos administrativos pudessem ser meramente objetivos. O tangenciamento do viés intersubjetivo é comprovado pelas marcas avaliativas empregadas estrategicamente pelo autor. $\mathrm{O}$ emprego da gradação evidencia os aspectos que distanciam os colonizadores portugueses dos habitantes locais. $\mathrm{O}$ uso dos três itens da atitude atua no texto, mormente, de maneira crítica em relação aos moradores da capitania.

Ao distanciar-se estrategicamente de seus governados, o Morgado de Mateus eleva seu ethos como superior, além de denotar toda a sua capacidade de observação. Em acréscimo, evidencia, pois, o seu comprometimento e a sua tenacidade enquanto governador e capitão-general da capitania de São Paulo, em detrimento dos habitantes da região, retratados ora como vítimas, ora como algozes da negligência e da preguiça.

\section{REFERÊNCIAS}

ARRUDA, J. J. de A. (coord.). Documentos manuscritos avulsos da Capitania de São Paulo - Catálogo 2 (1618 - 1823) - Mendes Gouveia. São Paulo: EDUSC, 2002. 804 p.

AZUAGA, L. (Org.). Relatos de Viagens: Representações e Codificações Linguísticas de Portugal no Século XIX. v. II. Lisboa: Centro de Estudos Anglísticos da Universidade de Lisboa, 2003. 168 p.

CAMBraiA, C. N.; CUNHA, A. G. da; MEgAlE, H. A Carta de Pero Vaz de Caminha. São Paulo: Série Diachronica 1, Humanitas, 2001. 89 p.

MARTIN, J.; WHITE, P. The language of evaluation: Appraisal in English. Basingstoke: Palgrave Macmillan, 2005. $256 \mathrm{p}$.

TAUNAY, A. E. Assuntos de três séculos coloniais (1598-1790). In: Anais do Museu Paulista. Tomo duodécimo. São Paulo: USP, 1945. 181 p.

VAN DIJK, T. A. Discurso e Poder. VAN DIJK, T. A.; HOFFNAGEL, J.; FALCONE, K. (org.). 2. ed. $1^{a}$ reimpressão. São Paulo: Contexto, 2012. 281 p.

Recebido em: 06/10/2015

Aprovado em: 12/07/2016 